\title{
Clinical education guideline creation by residents for junior learners in emergency medicine: a novel educational experience
}

\author{
Bandar Baw, MBBS; Teresa Chan, MD; Suneel Upadhye, MD, MSc
}

\section{ABSTRACT}

Clinical practice guidelines are an important vehicle for knowledge translation and improving patient care. For most learners, these documents can be daunting and confusing. We describe a novel educational experience that clarified the guideline generation process for learners while at the same time creating clinical educational guidelines (simplified learning aids) for junior learners in the emergency department (ED). We devised a system using near-peer mentors to generate a series of clinical education guideline learning materials created by residents and junior learners for the evaluation of undifferentiated chest pain in the ED. This process assisted in teaching residents and junior learners and generated an endurable educational product.

\section{RÉSUMÉ}

Les guides de pratique clinique sont un moyen important d'appliquer les connaissances et d'améliorer les soins aux patients. Toutefois, ces documents peuvent rebuter la plupart des stagiaires et créer de la confusion. Nous faisons état d'une expérience éducative innovante, qui a clarifié le processus d'élaboration des guides à l'intention des stagiaires tout en permettant de produire des guides éducatifs (matériel $d^{\prime}$ apprentissage simplifié) en matière de pratique clinique à l'intention des jeunes stagiaires au service des urgences (SU). Nous avons conçu un système ressemblant au mentorat par les pairs pour produire une série de documents d'apprentissage de type guide éducatif en matière de pratique clinique, élaborés par des résidents et de jeunes stagiaires sur l'évaluation de la douleur thoracique d'étiologie indéterminée au SU. L'exercice a aidé les résidents et les jeunes stagiaires à acquérir des connaissances, en plus de laisser du matériel éducatif durable.

Keywords: education, guidelines, medical students, residents

\section{BACKGROUND}

Exposure to evidence-based medicine (EBM) has become a core component of medical education within Canada. All Canadian medical specialties require residents to be well-versed in EBM principles, and many require residents to participate in the generation of new knowledge through scholarly and research-related projects.

Many barriers exist to implementing evidence from high-quality reviews and clinical practice guidelines (CPGs) into emergency medicine practice. ${ }^{1}$ Emergency physician-specific barriers include a lack of userfriendly "readable" writing formats, a lack of clarity of key recommendations, and a paucity of easily implementable application tools. ${ }^{2}$ For junior emergency medicine learners, finding and using guideline evidence can be particularly daunting.

We describe a novel educational experience that asked residents to review the evidence from the perspectives of a "near-peer" and "expert" in generating clinical education guidelines (CEGs) for clinical clerks and junior learners in the emergency department (ED). Internationally standardized methods of CPG creation were adapted to create CEGs focused on junior learners in the ED. The purpose of these guidelines was to provide a simplified evidence-based approach to key critical diagnoses related to the presentation of chest pain. The generation of these documents also provided residents with experience with guideline development.

\footnotetext{
From the Division of Emergency Medicine, Department of Medicine, McMaster University, Hamilton, ON.

Correspondence to: Dr. Teresa Chan, Division of Emergency Medicine, Department of Medicine, McMaster University, 247 Barton Street East, Hamilton, ON L8L 2X2; teresa.chan@medportal.ca.
}

This article has been peer reviewed. 


\section{RATIONALE}

There were two rationales for embarking on this project. The first was to create an evidence-based knowledge translation tool targeted to junior learners in the ED. "Near-peer mentors" are poorly defined in the literature but can be loosely described as a mentor that is near one's stage but slightly more advanced (e.g., as residents are for medical students). ${ }^{3}$ Near-peer mentors are often better able to synthesize and discriminate between essential information and nonessential information for their junior colleagues. ${ }^{3,4}$

The second rationale was to provide a hands-on experience for emergency medicine residents in the development of a clinical guideline. CPGs are the second highest level in the hierarchy of preappraised evidence. ${ }^{5}$ Residents are often asked to use these documents when reviewing topics and frequently use them to guide clinical care in the ED. However, very few residents have the experience of being involved in the development of guidelines. Through their participation in the CEG development process, residents were provided with the opportunity to become authors and reviewers while also gaining exposure to the Grading of Recommendations Assessment, Development and Evaluation (GRADE) system for evaluating evidence and creating recommendations (Table 1). ${ }^{6,7}$ Participating residents were also introduced to writing using internationally agreed upon standards..$^{6,8}$

\section{Table 1. The GRADE System}

Two judgments are made by the raters of the evidence:

1. Quality assessment of the evidence

- High: new research is unlikely to change the confidence of effect estimates

- Moderate: new research may impact effect estimates

- Low: further research is required and is very likely to impact effect estimates

- Very low: very uncertain about effect estimates

2. Recommendation strong or weak either for or against the particular intervention or test from the evaluators

- Strong recommendation: based on available evidence, the evaluators believe that this recommendation should be carried out (either for or against)

- Weak recommendation: based on available evidence, the evaluators believe that this recommendation may be carried out (either for or against)

Adapted from Guyatt $\mathrm{G}$ et al.

GRADE = Grading of Recommendations Assessment, Development and Evaluation

\section{DESCRIPTION OF THE INNOVATION}

Undifferentiated chest pain is a common and challenging presentation to the ED. The steps for creating a novel CEG to educate junior emergency medicine learners to address this condition are summarized in Table 2. These steps were generated by discussion with local experts who had studied or participated in guideline creation. ${ }^{9}$ Initial work was done by a core editorial group (B.B., S.U.) to determine the topics in a rigorous manner (see Table 2, steps 1-3). Subsequently, involving a large group of near-peer writers and editors created more approachable usable resources (see Table 2, steps 4-6). A comprehensive list of possible undifferentiated chest pain diagnoses was generated after review of various emergency medicine learning resources and the Medical Council of Canada Objectives MCC-1 document (3rd edition). ${ }^{10}$ Emergency medicine faculty members at McMaster University were surveyed to identify essential "can't miss" diagnoses from this list." The final diagnoses were acute coronary syndrome (including ST elevation myocardial infarction, non-ST elevation myocardial infarction, and unstable angina), pulmonary embolism, thoracic aortic dissection, pneumothorax, and community-acquired pneumonia.

Four key CEG questions involving clinical assessment, investigations, risk stratification, and initial management were generated for each diagnosis. The current literature (including guidelines, policies, and Cochrane reviews) was reviewed for high-quality evidence summaries that could be reframed in a manner appropriate for a CEG for junior learners.

We then recruited nine residents and one senior medical student to research and create junior learnerfriendly educational materials. Each of these volunteers was assigned to a team that reviewed and rewrote the evidence appraisal for the targeted junior learners using Appraisal of Guidelines for Research and Evaluation (AGREE) reporting standards. ${ }^{8}$ Authors were paired for writing assignments, and a consensus group meeting was held to obtain agreement on various recommendations using GRADE principles. ${ }^{7}$ Final drafts were circulated to expert and subspecialty faculty members for review or endorsement, as well as junior learners for acceptability of the CEG materials (which was defined as utility in learning or clinical practice). Survey responses during the review or endorsement phase were used to make final revisions for the CEG prior to its implementation in the McMaster University emergency medicine clerkship 
Table 2. Steps in creating CEG for junior EM learners

\begin{tabular}{|c|c|}
\hline Step & Methods \\
\hline Creation of working group & ED faculty, EM residents of various levels \\
\hline \multirow[t]{3}{*}{ Formulation of key questions/review processes } & 1. Development of key questions (4) \\
\hline & $\begin{array}{l}\text { 2. Review of GRADE system for grading evidence and making } \\
\text { recommendations }\end{array}$ \\
\hline & 3. Review of AGREE reporting standards \\
\hline \multirow[t]{2}{*}{ Selection of common ED chief complaint } & $\begin{array}{l}\text { Review of traditional EM teaching textbooks, study guides, Canadian } \\
\text { MCC training objectives (LMCC-1), US/European EM }\end{array}$ \\
\hline & Model national training curricula \\
\hline \multirow[t]{2}{*}{ Generating a list of key and sentinel diagnoses } & 1. Review of above materials for all possible candidate diagnoses \\
\hline & $\begin{array}{l}\text { 2. Survey of EM teaching faculty to prioritize essential "can't miss" } \\
\text { diagnoses for chief complaint }\end{array}$ \\
\hline Evidence review & $\begin{array}{l}\text { Review of all summarized practice guidelines, systematic reviews/ } \\
\text { meta-analyses, clinical policies published in medical literature }\end{array}$ \\
\hline \multirow[t]{2}{*}{ Draft CEG creation } & $\begin{array}{l}\text { 1. Writing teams to answer key questions for each sentinel diagnosis } \\
\text { (AGREE methodology) }\end{array}$ \\
\hline & 2. Initial GRADE recommendations \\
\hline \multirow[t]{2}{*}{ Working group overall review } & 1. Presentation of draft CEG documents by writing teams \\
\hline & $\begin{array}{l}\text { 2. Consensus GRADE evaluation of recommendations; conflict } \\
\text { resolution using GRADE } \text { grid }^{6}\end{array}$ \\
\hline \multirow[t]{2}{*}{ Evaluation of draft CEG to content experts and stakeholders } & $\begin{array}{l}\text { 1. Distribution for content/recommendations review to EM and internal } \\
\text { medicine faculty for feedback }\end{array}$ \\
\hline & 2. Distribution to junior learners for feedback and acceptability \\
\hline Implementation & Implementation into McMaster EM clerkship curriculum \\
\hline
\end{tabular}

AGREE = Appraisal of Guidelines for Research and Evaluation; $C E G=$ clinical education guideline; $E D=$ emergency department; EM = emergency medicine; GRADE = Grading of Recommendations Assessment, Development and Evaluation; LMCC-1 = the Licentiate of Medical Council of Canada, Part One Exam; MCC = Medical Council of Canada.

curriculum. The final chest pain CEGs are available at the McMaster Emergency Medicine Undergraduate Medical Education website: <http://fhs.mcmaster.ca/ emergmed/undergrad_guidelines.htm $>$. The entire process took approximately 3 years to complete, which meant that many of our near-peers were faculty members by the end of the project arc.

\section{DISCUSSION}

We have described a successful, near-peer edited process to collaboratively generate useful resources for junior emergency medicine learners. During the evaluation phase, stakeholders and EBM experts from a diverse panel of specialties found the material to be acceptable and trustworthy. The process we outline is reproducible for those who wish to enhance learning resources for this target audience. This innovation would merge well with the recently published consensus list of core competencies for Canadian emergency medicine clerkships and provide a framework to produce educational materials to teach these items. $^{11}$

\section{SUMMARY}

The development of CEGs is an instructional method that can be used to accomplish two goals: 1) the production of near-peer authored educational materials targeted to junior learners and 2) the provision of resident exposure to the process of guideline authorship, including the use of the AGREE and GRADE systems. The framework we describe would allow Canadian emergency medicine educators to produce teaching products consistent with a national consensus curriculum.

Acknowledgements: We acknowledge the authors of the first edition of the CEGs for their hard work: Julien Payrastre, Julian Owen, Jay MacDonald, Damon Atrie, Claire Kenny-Scherber, Karen Schiff, and George Montgomery. We also thank Jonathan Sherbino for his advice on the manuscript.

Competing interests: None declared.

\section{REFERENCES}

1. Cabana MD, Rand CS, Powe NR, et al. Why don't physicians follow clinical practice guidelines? A framework 
for improvement. $7 A M A$ 1999;282:1458-65, doi:10.1001/ jama.282.15.1458.

2. Aboulsoud S, Huckson S, Wyer P, Lang E. Survey of preferred guideline attributes: what helps make guidelines more useful for emergency health practitioners? Int 7 Emerg Med 2012;5:42, doi:10.1186/1865-1380-5-42.

3. Ramani S, Gruppen L, Kachur EK. Twelve tips for developing effective mentors. Med Teach 2006;28:404-8, doi: $10.1080 / 01421590600825326$.

4. Kam JK, Tai J, Mitchell RD, et al. A vertical study programme for medical students: peer-assisted learning in practice. Med Teach 2013;35:e943, doi:10.3109/0142159X. 2012.715782.

5. DiCenso A, Bayley L, Haynes RB. Accessing preappraised evidence: fine-tuning the $5 \mathrm{~S}$ model into a $6 \mathrm{~S}$ model. $A C P \mathrm{~F}$ Club 2009;151:JC3-2.

6. Jaeschke R, Guyatt GH, Dellinger P, et al. Use of GRADE grid to reach decisions on clinical practice guidelines when consensus is elusive. BM7 2008;337:a744, doi:10.1136/bmj. a744.

7. Guyatt G, Oxman AD, Alk EA, et al. GRADE guidelines: 1. Introduction-GRADE evidence profiles and summary of findings tables. 7 Clin Epidemiol 2011;64:383-94, doi:10. 1016/j.jclinepi.2010.04.026.

8. AGREE Trust. Available at: http://www.agreetrust.org (accessed June 15, 2013).

9. Baw B, Upadhye S. Creation of a clinical education guideline for undifferentiated chest pain assessment for junior learners: a methodological framework [abstract]. CFEM 2010;12:271.

10. Medical Council of Canada. Objectives for the Qualifying Examination (3rd Edition 3.3.8). Available at: http://apps.mcc. ca/Objectives_Online/objectives.pl?loc=home\&lang=english (accessed on June 15, 2013).

11. Penciner R, Woods RA, McEwen J, et al. Core competencies for emergency medicine clerkships: results of a Canadian initiative. Can 7 Emerg Med 2013;15:24-33. 